\title{
Surgical management of follicular thyroid carcinoma in children and adolescents: A study of 30 cases
}

\author{
Claudio Spinelli ${ }^{\mathrm{a}, *}$, Leonardo Rallo ${ }^{\mathrm{a}}$, Riccardo Morganti ${ }^{\mathrm{b}}$, Valentina Mazzotti ${ }^{\mathrm{b}}$, Alessandro Inserra ${ }^{\mathrm{c}}$, \\ Giovanni Cecchetto ${ }^{\mathrm{d}}$, Maura Massimino ${ }^{\mathrm{e}}$, Paola Collini ${ }^{\mathrm{f}}$, Silvia Strambi ${ }^{\mathrm{a}}$ \\ a Pediatric and Adolescent Surgery Division, University of Pisa, Italy \\ b Statistical Support to Clinical Trials Department, University of Pisa, Italy \\ c Pediatric Surgery Division, Bambino Gesù Institute, Rome, Italy \\ d Pediatric Surgery Division, University of Padua, Italy \\ e Pediatric Oncology Unit, IRCCS Istituto Nazionale dei Tumori, Milan, Italy \\ ${ }^{\mathrm{f}}$ Soft Tissue and Bone Pathology, Histopathology and Pediatric Pathology Unit, IRCCS Istituto Nazionale dei, Tumori, Milan, Italy
}

\section{A R T I C L E I N F O}

\section{Article history:}

Received 16 January 2018

Received in revised form 24 April 2018

Accepted 23 May 2018

Available online $\mathrm{xxxx}$

\section{Key words:}

Pediatric thyroid cancer

Follicular thyroid cancer

Children

Adolescents

Surgery

\begin{abstract}
A B S T R A C T
Background/Purpose: The purpose of the study is to describe the anatomoclinical, diagnostic, therapeutic and prognostic aspects of pediatric follicular thyroid carcinoma (FTC) in order to choose the best therapeutic strategy. Methods: Our study includes patients $\leq 18$ years old surgically treated for FTC in four Italian Pediatric Surgery Centers from January 2000 to March 2017. The collected data were compared with those of 132 patients matched for age with a histological diagnosis of papillary thyroid carcinoma (PTC) surgically treated in the same institutions during the same period and with the data of patients diagnosed with FTC found in the literature; $p$-values $<0.05$ were considered significant.

Results: 21 (70\%) of the 30 patients with a histological diagnosis of FTC underwent hemithyroidectomy while 9 (30\%) underwent total thyroidectomy. 11 (55\%) out of 21 patients were subjected to a completion of thyroidectomy. All patients are alive (OS $=100 \%$ ) without recurrence or relapse of the disease. Compared with PTC, FTC is significant for capsule infiltration $(\mathrm{p}<0.0001)$, vascular invasion $(\mathrm{p}=0.0014)$ and T-stage T3-T4 $(\mathrm{p}=0.013)$. However, multifocality $(p<0.001)$, extrathyroid extension $(p<0.0001)$ and lymph node metastasis $(\mathrm{p}<0.0001)$ are more evident in PTC.

Conclusion: The conservative approach seems to be a valid surgical treatment for pediatric patients diagnosed with MI-FTC. For patients with wide vascular invasion and/or a tumor $>4 \mathrm{~cm}$, especially with high aftersurgery Tg rate, a completion of thyroidectomy is recommended. In patients with multifocal neoplasia, and/or tumor size $\geq 4 \mathrm{~cm}$, and/or extrathyroid extension, and/or lymph node metastasis, and/or distant metastasis, total thyroidectomy followed by radioiodine therapy is generally indicated.

Levels of Evidence: II.
\end{abstract}

(c) 2018 Elsevier Inc. All rights reserved.
Thyroid carcinoma represents the most common endocrine neoplasia during pediatric age, with an incidence of $0.4-0.7$ cases out of 100,000 children and adolescents between 0 and 18 years old. The most common type (about 90\%) in children and adolescents is papillary

Abbreviations: FTC, Follicular Thyroid Carcinoma; DTC, Differentiated Thyroid Carcinoma; PTC, Papillary Thyroid Carcinoma; LN, lymph node; FNAC, Fine Needle Aspiration Cytology; US, Ultrasonography; MI-FTC, Minimally Invasive Follicular Thyroid Carcinoma; WI-FTC Widely Invasive, Follicular Thyroid Carcinoma; RAI, Radioactive Iodine-Therapy; TT, Total Thyroidectomy; HT, Hemithyroidectomy; TC, Completion of Thyroidectomy.

* Corresponding author at: Pediatric and Adolescent Surgery Division, Department of Surgical, Medical, Pathological, Molecular and Critical Area, University of Pisa, Italy, Via Paradisa 2, 56124, Pisa, Italy. Tel.: + 39 3334069061; fax: + 39050997707.

E-mail address: c.spinelli@dc.med.unipi.it. (C. Spinelli). thyroid carcinoma (PTC), followed by follicular thyroid carcinoma. The incidence of both types increases by about $1 \%$ each year, while the prevalence decreases over time [1-12]. Iodine deficiency and exposure to ionizing radiations represent the main risk factors of FTC [13-17]. In patients treated with radiotherapy for Hodgkin's Lymphoma, leukemia or central nervous system tumors, the FTC incidence reaches $2 \%$ each year, with a peak occurring 15-25 years after exposure [18-24]. In some geographical areas, the FTC percentage of all the differentiated thyroid cancers (DTC) increases by 40 (for example, in Byelorussia and Ukraine after the nuclear disaster of Chernobyl) [13-16]. Alterations in RAS, PIK3CA, PAX8/PPAR $\gamma$ genes seem to have an important role especially in adult FTC [25-27]. FTC is included in the components of the PTEN Hamartoma Tumor Syndrome, including the Cowden Syndrome, caused by germinal mutations in PTEN [28-33]. 
FTC is classified in Minimally Invasive-FTC (MI-FTC) and in Widely Invasive-FTC (WI-FTC). Encapsulated neoplasms with microscopic tumor capsule invasion and/or limited vascular invasion are defined as MI-FTC. Large invasive neoplasms, lack of complete tumor encapsulation, multifocality, extended vascular invasion, widespread invasion in thyroid parenchyma and/or adjacent tissues are features of WI-FTC [34-38]. The postoperative histological diagnosis is based on the identification of these features. Fine needle aspiration cytology (FNAC) is insufficient for the diagnosis of FTC, although diagnostic sensibility is included between $65 \%$ to $98 \%$ while specificity is $73 \%$ to $100 \%[37,39]$. However, an intraoperative histological examination on frozen sections is not recommended for a diagnosis of MI-FTC owing to the difficulty in differentiating an MI-FTC from a follicular adenoma or from a PTC encapsulated follicular variant [40]. Although WI-FTC has generally a worse prognosis in adult patients, it is reported similar to MI-FTC in children and adolescents $[11,12,41,42]$. A bias owing to a misdiagnosis of PTC, a follicular variant, cannot be excluded.

There are only a few articles on FTC in pediatric and adolescent age in the literature. Many studies associate FTC to PTC in their surgical approach, although the two neoplasms have different clinical and pathological characteristics. Furthermore, thyroidectomy extension in FTC treatment is still debated $[9,42,43]$. Our study describes the anatomoclinical, therapeutic and prognostic characteristics of pediatric and adolescent patients affected by FTC compared with our pediatric patients affected by PTC and with pediatric patients affected by FTC reported in the literature from 1997 to 2017. The most relevant articles published in Pubmed and/or Google Scholar on pediatric FTC consist mostly of case reports $[43,44]$ with the exception of Enomoto et al. [42], who report the surgical experience of 20 patients aged between 11 and 20 years old. The purpose of our study is to significantly contribute to the surgical approach of FTC in pediatric and adolescent patients.

\section{Materials and methods}

This retrospective study is based on the observation of FTC patient $\leq 18$ years old, in a 17 year period (January 2000-March 2017), operated at the Pediatric and Adolescent Surgery Division of the University of Pisa, the Pediatric Surgery Division of the University of Padua, the Pediatric Surgery Division of Bambino Gesú Children Hospital in Rome and the Surgery Division of "Istituto Nazionale dei Tumori" in Milan. The studied variables were: age at diagnosis, sex, medical history, clinical presentation, diagnostic tests (thyroid US; chest X-Ray; FNAC; thyroid scintigraphy; neck MRI), surgical therapy (total thyroidectomy TT; hemithyroidectomy HT; completion of thyroidectomy TC), cervical lymphadenectomy (central lymph nodes compartment and lateral lymph nodes compartment), histological type (FTC classical form, FTC Hürtle cell variant), WHO classification (minimally invasive MI-FTC, widely invasive WI-FTC), tumor capsule invasion, vascular invasion, multifocality and TNM staging [45]. Furthermore, postoperative complications (transitory hypoparathyroidism; definitive hypoparathyroidism; injury of the recurrent laryngeal nerve), postoperative treatment (hormonal manipulation and radioactive iodine-therapy, RAI) and follow up were analyzed. All patients, after both radical and conservative surgery, were subjected to hormonal therapy (thyroid-stimulating hormone suppression) with a Levo-Thyroxin dose (according to the patients' age and weight) to obtain an optimal value of TSH $<0.3 \mathrm{UI} / \mathrm{ml}$, to control neoplastic proliferation and to prevent the progression and recovery of disease [46]. Radioactive iodine remnant ablation was performed within 6 weeks after radical surgery, following ATA guidelines [47].

The follow-up after TT consisted in laboratory tests and instrumental exams: calcium serum level, dosage of thyroid hormones (TSH, FT3, FT4, $\mathrm{Tg}$, anti-Tg Ab), thyroid US and total-body scintigraphy. The monitoring of thyroglobulin $(\mathrm{Tg})$ levels was employed for the detection of disease recurrences [48].
The first postoperative follow-up was done after about 6 weeks in a hypothyroid state using a total-body scintigraphy with iodine-131. A total body scintigraphy was repeated after 6-12 months from the first one, after an appropriate suspension of the suppressive therapy. At the end of the follow-up, patients were considered without clinic evidence of disease if they had: serum suppression of the thyroglobulin ( $\mathrm{Tg}$ $<1 \mathrm{ng} / \mathrm{mL}$ ), lack of antithyroglobulin antibodies (anti-Tg Ab), total lack of local or distant disease at imaging (US, CT, X-Ray) and/or positivity of disease to control biopsy. The follow-up after-HT included: a clinical test, a yearly chest X-Ray and a serum dosage of thyroid hormones (FT3, FT4, TSH, Tg and anti-Tg Ab) every 6 months during the first 2 years, then annually. The reference value for $\mathrm{Tg}$ obtained one month after surgical treatment was considered between 0 and $5 \mathrm{ng} / \mathrm{mL}$. The thyroid US was performed two times a year during the first 5 years, then yearly [6]. The data of patients diagnosed with FTC were compared with those of 132 patients of the same age with histological diagnosis of PTC, subjected to TT in the same institutes and during the same years and with the data of 20 young patients operated for FTC found in the literature [42].

\subsection{Data analysis}

Categorical data were described by frequency, whereas continuous data were described by mean and standard deviation. To evaluate the normality of the quantitative data distributions, the KolmogorovSmirnov test was performed. The assessment of the qualitative variables was realized by the z-test for proportions and by the chi-square test, whereas the quantitative variables were analyzed with the $t$ test (twotailed). Finally, a correlation analysis between tumor size and age was carried out with the Pearson Method. The value of $\mathrm{p}<0.05$ was considered statistically significant and the p-value between 0.05 and 0.1 indicated a "trend toward significance". All analyses, descriptive and inferential, were performed using SPSS v.24 technology.

\section{Theory}

To date, surgical indications for FTC and PTC in pediatric age have not been very dissimilar. An in-depth knowledge of the anatomoclinical and prognostic aspects of both carcinomas, obtained through our statistical correlation on patients treated in the same period in four major university centers, contributes to a more appropriate management of these neoplasms and helps select patients who need to be treated with a conservative approach from those who need to be treated with a radical surgical one. This study also deals with the relevant issues concerning the evaluation and treatment of cervical lymph nodes and the postoperative radioiodine therapy adopted. Moreover, it lays the groundwork for further investigation so that every pediatric patient affected by thyroid carcinoma may have a tailored surgical treatment.

\section{Results}

Between January 2000 and March 2017, 30 patients with a histological diagnosis of FTC were surgically treated and diagnosed in referral centers for thyroid pathologies. Dedicated pediatric thyroid pathologists performed all diagnoses. There were 8 (27\%) males and 22 (73\%) females. The age range was $5-18$ years: 18 cases $(60 \%) \leq 15$ years old and $12(40 \%)>15$ years old. Mean age at the time of diagnosis was $13.73 \pm 3.83$ years: $13.75 \pm 4.86$ years old for males, and $13.73 \pm$ 3.52 years old for females. The age division is reported in Table 1. Nine patients (30\%) were familiar to thyroid disease and all of them reported a history of multinodular goiter.

At the objective examination, 21 patients (70\%) had a cervical tumefaction in the anterolateral region of the neck, while the diagnosis was accidental in the remaining 9 patients (30\%), because a thyroid examination was performed during total body screening US. These patients did not present a statistically significant difference from the rest of the 
Table 1

Frequency of patients for age at diagnosis and sex.

\begin{tabular}{lccll}
\hline Age (years) & Number of patients & Pts \% & Males \% & Females \% \\
\hline $0-5$ & 2 & 7 & 50 & 50 \\
$6-10$ & 5 & 17 & 20 & 80 \\
$11-15$ & 11 & 36 & 18 & 82 \\
$16-18$ & 12 & 40 & 33 & 67 \\
\hline
\end{tabular}

cohort, either by gender, age or familiarity. The size of the follicular lesion was generally smaller in patients with an incidental diagnosis: average size of tumor was $16.1 \mathrm{~mm}$ (range $7-24 \mathrm{~mm}$ ) vs. $25.8 \mathrm{~mm}$ (range 7-75 mm).

All 30 patients underwent thyroid US (100\%), and 25 of them also underwent FNAC (83\%), 13 patients (43.3\%) had a chest X-Ray, one patient $(0,03 \%)$ had a thyroid scintigraphy and one patient $(0,03 \%)$ had an MRI. Patients were surgically treated by four pediatric surgeon, each belonging to one of the four hospitals; 21 patients were operated in Pisa, 4 patients in Padua, 3 in Milan and 2 in Rome.

The surgical therapy was conservative (HT) in 21 patients (70\%) and radical (TT) in 9 patients (30\%). For the 21 patients subjected to a conservative surgical treatment as a first approach, 11 (52\%) were operated a second time with completion of thyroidectomy (TC) after their definitive histological report. A lymphadenectomy of the central and lateral cervical section was performed in 3 patients (10\%) owing to clinically suspected metastatic lesions. Postoperative complications occurred in 7 patients (23\%), 5 (71.4\%) after a TT and 2 (28.6\%) after a TC; a transitory hypoparathyroidism occurred in 4 patients (57\%); a definitive hypoparathyroidism occurred in $2(28 \%)$ and a lesion of the recurrent laryngeal nerve occurred in one patient (15\%). As detailed in Table 2 , 28 were MI-FTCs (93.4\%) and 2 (6.6\%) were WI-FTCs. Of the MI-FTCs, tumor capsule invasion was present in all cases, while vascular invasion was present in 9 patients (30\%). There weren't any cases of multifocality in the thyroid parenchyma. The 2 cases of WI-FTC were diagnosed on the basis of large invasive neoplasms tumor size, lack of complete tumor encapsulation, multifocality, extended vascular invasion ( $>3$ vascular foci), widespread invasion into thyroid parenchyma and/or adjacent tissue characterization. None of the three patients subjected to lymph nodal dissection had lymph nodal metastasis at the histological examination. The average size of tumor was $25.81 \pm 16.92 \mathrm{~mm}$ (range: 7-75 mm). According to TNM [45], classification of T was: T1a (Tumor $\leq 1 \mathrm{~cm}$, limited to the thyroid) in 3 patients $(10 \%)$; $1 \mathrm{~b}$ (Tumor $>1 \mathrm{~cm}$ but $\leq 2 \mathrm{~cm}$ in greatest dimension, limited to the thyroid) in 10 (33\%); $\mathrm{T} 2$ (Tumor size $>2 \mathrm{~cm}$ but $\leq 4 \mathrm{~cm}$, limited to the thyroid) in $12(40 \%)$; T3 (Tumor size $>4 \mathrm{~cm}$, limited to the thyroid or any tumor with minimal extrathyroidal extension to sternothyroid muscle or perithyroid soft tissues) in 5 (17\%) [45]. The correlation between tumor size and age at time of diagnosis was not statistically significant

Table 2

FTC and PTC histological types and classification.

\begin{tabular}{ll}
\hline FTC type & Number of cases (\%) \\
\hline Minimally Invasive Follicular thyroid carcinoma (MI-FTC) & $28(93,4)$ \\
Minimally Invasive Follicular Carcinoma, NOS & $20(66.7)$ \\
Minimally Invasive Follicular Carcinoma, Hürtle-cell variant & $8(26.7)$ \\
Widely Invasive Follicular thyroid carcinoma (WI-FTC) & $2(6.6)$ \\
& \\
PTC type & Number of cases (\%) \\
\hline Conventional variant of PTC & $75(56.8)$ \\
Follicular variant of PTC & $37(28)$ \\
Diffuse sclerosing variant & $7(5.3)$ \\
Tall cell variant & $7(5.3)$ \\
Trabecular variant & $4(3)$ \\
Poorly differentiated variant & $2(1.6)$ \\
\hline
\end{tabular}

( $p=0,277)$. None of the cases had lymph nodal metastasis (N0) and/ or distant metastasis (M0). The mean follow-up was $72.8 \pm$ 34.62 months (6-120 months range). All our patients are alive and well (OS $=100 \%)$. No patient has shown any recurrence of disease or after-surgery relapse. Regarding postoperative treatments, 8 patients (27\%) executed an adjuvant RAI treatment after TT. All patients have been treated with TSH-suppressive action substitutive Levo-Thyroxin. The statistical analysis of 30 FTC patients (18.5\%) and 132 PTC patients $(81.5 \%)$ is reported in Table 3. Starting from hypothesis zero which states that PTC and FTC have identical clinical characteristics in patients and the hypothesis that there are overlapping data in terms of clinical characteristics and treatment, we made adequate statistical tests. Pvalues $>0.05$ did not result significant and confirmed the similarity between the compared patients, while $\mathrm{p}$-values $\leq 0.05$ showed the substantial differences between the two groups. Compared to the PTC, FTC was significantly associated with tumor capsule invasion $(\mathrm{p}<0.0001)$, vascular invasion $(\mathrm{p}=0.014)$ and $\mathrm{T}$ stage T3-T4 $(\mathrm{p}=$ $0.013)$.

Multifocality ( $p<0.0001)$, extrathyroid extension $(\mathrm{p}<0.0001)$ and lymph-nodal metastasis ( $\mathrm{p}<0.0001$ ) were associated with PTC. Compared to the data we found in the literature, the type of surgical treatment is significant ( $p=0.071 ; p=0.037$ ). This fact shows the clear difference in the choice of surgical treatment in our study; that is, we performed more primary TT and more TC compared to Enomoto [42] (Table 4).

\section{Discussion}

FTC in pediatric and adolescent age is very rare and there are not enough studies on it. It represents $10 \%-20 \%$ of the DTCs and the most frequent variant after PTC $[3,45]$. Current guidelines and scientific articles often group the two neoplasms together, even though they behave differently in terms of aggressiveness, nodal and distant metastasis pattern and recurrence of disease. The choice of the surgical treatment (HT vs. TT and completion vs. not completion) is still controversial owing to the limited amount of studies in the literature. Enomoto study [42] has the biggest case series found in the literature, with 20 cases of FTC (aged between 11 and 20 years). Thus, to our knowledge, our current study on 30 cases (aged between 5 and 18 years) is the most extensive and its results contribute to our knowledge of FTC during pediatric and adolescent age. In our series, FTC represents $18.5 \%$ of DTC, with a peak incidence in 16-18 year olds and a prevalence in females ( $\mathrm{M}: \mathrm{F}=1: 3)$. In addition, our patients are highly familiar with multinodular goiter ( $30 \%$ of patients). We believe that this datum deserves attention because there is a potential genetic interest both for multinodular goiter and follicular cell-derived well-differentiated thyroid cancer, as reported in the recent literature $[49,50]$. Our study confirms the different clinical-pathologic scenario between FTC and PTC in pediatric age with respect to PTC; pediatric FTC may be less aggressive and associated with less advanced disease, fewer distant metastases and a lower rate of recurrence. FTC exceptionally spreads to regional lymph nodes, but it is subjected to vascular spread and distant metastases mainly at lung and bone without contemporaneous lymph nodal involvement [44]. MI-FTC is typically uninodular while WI-FTC largely involves the thyroid parenchyma [37]. Neoplasia is often present in remarkable dimensions: in fact, more than $50 \%$ of our cases presented a neoplastic mass $>2 \mathrm{~cm}$. Behavior is dramatically different between the two forms: MI-FTC is a quite indolent tumor, whereas WI-FTC can be an ominous tumor. In accordance with the literature and at variance with adult age, MI-FTC represents about $90 \%$ of cases, with good outcome. This fact explains the very good prognosis of FTC in pediatric age, similar to PTC $[37,42,51,52]$. Regarding lymph nodal metastasis, our patients and Enomoto et al. study patients are similar enough with a nonsignificant $p$-value $(p=0.803)$. All patients with MI-FTC presented a tumor capsular invasion which essentially differentiates a follicular adenoma from a FTC. $30 \%-45 \%$ of the patients presented a vascular invasion, but 
Table 3

Clinical and pathological correlations between PTC patients' and FTC patients' characteristics.

\begin{tabular}{|c|c|c|c|}
\hline & Value PTC & Value FTC & p-value \\
\hline Patients, n & 132 & 30 & \\
\hline \multicolumn{4}{|l|}{ Gender, n (\%) } \\
\hline Female & $100(75.8)$ & $22(73.3)$ & 0.965 \\
\hline Male & $32(24.2)$ & $8(26.7)$ & \\
\hline Female/male Ratio & 3.1 & 2.7 & \\
\hline \multicolumn{4}{|l|}{ Age, years } \\
\hline Mean +/-SD & $14.3 \pm 3.5$ & $13.7 \pm 3.8$ & 0.405 \\
\hline Range & $4-18$ & $5-18$ & \\
\hline$\leq 15$ & $69(52.3)$ & $18(60)$ & 0.573 \\
\hline$>15$ & $63(47.7)$ & $12(40)$ & \\
\hline \multicolumn{4}{|l|}{ Tumor size, $(\mathrm{cm})$} \\
\hline Mean \pm SD & $2.4 \pm 1.7$ & $2.58 \pm 1.69$ & 0.562 \\
\hline$\leq 1$ & $17(12.9)$ & $3(10)$ & \\
\hline $1.1-2$ & $52(39.4)$ & $11(36.6)$ & 0.999 \\
\hline $2.1-4$ & $45(34.1)$ & $12(40)$ & \\
\hline$>4$ & $18(13.6)$ & $4(13,4)$ & \\
\hline Infiltration of the thyroid capsule, $n$ (\%) & & & $<0.01$ \\
\hline Yes & $73(55.3)$ & $30(100)$ & \\
\hline No & $59(44.7)$ & 0 & \\
\hline Vascular invasion, $\mathbf{n}(\%)$ & & & 0.014 \\
\hline Yes & $14(10.6)$ & $9(30)$ & \\
\hline No & $118(89.4)$ & $21(70)$ & \\
\hline Multifocality, n (\%) & & & $<0.0001$ \\
\hline Yes & $51(38.6)$ & $0(0)$ & \\
\hline No & $81(61.4)$ & $30(100)$ & \\
\hline Homolateral & $16(12.1)$ & $0(0)$ & \\
\hline Bilateral & $35(26.5)$ & $0(0)$ & \\
\hline \multicolumn{4}{|l|}{ Extrathyroid Extension } \\
\hline Yes & $63(47,7)$ & $0(0)$ & $<0.0001$ \\
\hline No & $69(53,3)$ & $30(100)$ & \\
\hline \multicolumn{4}{|l|}{ T stage, $\mathbf{n}(\%)$} \\
\hline $\mathrm{T} 1$ & $41(31.1)$ & $13(43)$ & 0.301 \\
\hline $\mathrm{T} 2$ & $28(21.2)$ & $12(40)$ & 0.055 \\
\hline T3 & $54(40.9)$ & $5(17)$ & 0.025 \\
\hline $\mathrm{T} 4$ & $9(6.8)$ & $0(0)$ & 0.304 \\
\hline T3-T4 & $63(47.7)$ & $5(16.7)$ & 0.013 \\
\hline \multicolumn{4}{|l|}{ N stage, n (\%) } \\
\hline NO & $59(44.7)$ & $30(100)$ & $<0.0001$ \\
\hline N1 & $73(55.3)$ & $0(0)$ & \\
\hline Lymph node metastasis, n (\%) & $73(55.3)$ & $0(0)$ & \\
\hline Central only & $17(12.9)$ & $0(0)$ & \\
\hline Lateral only & $25(18.9)$ & $0(0)$ & \\
\hline Central and lateral & $31(23.5)$ & $0(0)$ & \\
\hline \multicolumn{4}{|l|}{ M stage, n (\%) } \\
\hline M0 & $122(92.4)$ & $30(100)$ & 0.256 \\
\hline M1 & $10(7.6)$ & $0(0)$ & \\
\hline \multicolumn{4}{|l|}{ Radioiodine Treatment, n (\%) } \\
\hline Yes & $130(98.5)$ & $8(27)$ & $<0.0001$ \\
\hline No & $2(1.5)$ & $22(73)$ & \\
\hline \multicolumn{4}{|l|}{ Follow up, (years) } \\
\hline Mean \pm SD & $4.7 \pm 2.3$ & $6 \pm 3.46$ & 0.013 \\
\hline Range & $1-14$ & $0.5-10$ & \\
\hline \multicolumn{4}{|l|}{ Persistence, n (\%) } \\
\hline Complete remission & $119(90.2)$ & $30(100)$ & 0.156 \\
\hline Persistence of disease & $13(9.8)$ & 0 & \\
\hline \multicolumn{4}{|l|}{ Recurrence, n (\%) } \\
\hline Thyroid bed & $5(3.8)$ & $0(0)$ & 0.617 \\
\hline Lymph nodal & $6(4.5)$ & $0(0)$ & 0.518 \\
\hline Lung & $2(1.5)$ & $0(0)$ & 0.806 \\
\hline Total & $13(9.8)$ & $0(0)$ & 0.157 \\
\hline
\end{tabular}

this was not statistically significant $(\mathrm{p}=0.434)$ compared to the Enomoto et al. study FTCs, while it was significant compared to the PTCs $(p=0.014)$. In the literature, the negative impact of the vascular invasion is not the same for all the authors [53,54]. The histotype, tumor size, capsular and/or vascular invasion, age, sex, prognosis and
Table 4

Clinical and pathological correlations between our FTC patients' and Enomoto et al. [42] FTC patients' characteristics.

\begin{tabular}{|c|c|c|c|}
\hline & Value FTC & $\begin{array}{l}\text { Value FTC } \\
\text { Enomoto }\end{array}$ & p-value \\
\hline Patients, n & 30 & 20 & \\
\hline \multicolumn{4}{|l|}{ Gender, n (\%) } \\
\hline Female & $22(73)$ & $18(90)$ & 0.279 \\
\hline Male & $8(27)$ & $2(10)$ & \\
\hline Female/Male Ratio & 2.7 & 9 & \\
\hline \multicolumn{4}{|l|}{ Age, (years) } \\
\hline Mean $+/-$ SD & $13.7 \pm 3.8$ & $17.3 \pm 2.7$ & $<0.0001$ \\
\hline Range & $5-18$ & $11-20$ & \\
\hline$\leq 15$ & $18(60)$ & $5(25)$ & 0.032 \\
\hline$>15$ & $12(40)$ & $15(75)$ & \\
\hline \multicolumn{4}{|l|}{ Tumor size, (cm) } \\
\hline Mean \pm SD & $2.6 \pm 1.7$ & $2.94 \pm 2.2$ & 0.590 \\
\hline$\leq 1$ & $3(10)$ & $3(15)$ & \\
\hline $1.1-2$ & $11(36.6)$ & $6(30)$ & \\
\hline $2.1-4$ & $12(40)$ & $6(30)$ & 0.888 \\
\hline$>4$ & $4(13.4)$ & $5(25)$ & \\
\hline \multicolumn{4}{|l|}{ Histologic feature, n (\%) } \\
\hline Minimally invasive FTC & $28(93.4)$ & $16(80)$ & 0.025 \\
\hline Widely invasive FTC & $2(6.6)$ & $4(20)$ & \\
\hline \multicolumn{4}{|c|}{ Infiltration of the thyroid capsule, $n$ (\%) } \\
\hline Yes & $30(100)$ & $20(100)$ & 0.999 \\
\hline No & 0 & 0 & \\
\hline \multicolumn{4}{|l|}{ Vascular invasion, $\mathbf{n}(\%)$} \\
\hline Yes & $9(30)$ & $9(45)$ & 0.434 \\
\hline No & $21(70)$ & $11(55)$ & \\
\hline \multicolumn{4}{|l|}{ T stage, n (\%) } \\
\hline $\mathrm{T} 1$ & $13(43.3)$ & $9(45)$ & 0.863 \\
\hline $\mathrm{T} 2$ & $12(40)$ & $6(30)$ & 0.674 \\
\hline T3 & $5(16.7)$ & $5(25)$ & 0.720 \\
\hline $\mathrm{T} 4$ & 0 & 0 & \\
\hline \multicolumn{4}{|l|}{ N stage, $\mathbf{n}(\%)$} \\
\hline No & $30(100)$ & $19(95)$ & 0.803 \\
\hline N1 & $0(0)$ & $1(5)$ & \\
\hline Central only & $0(0)$ & $1(100)$ & \\
\hline Lateral only & $0(0)$ & 0 & \\
\hline Central and lateral & $0(0)$ & 0 & \\
\hline \multicolumn{4}{|l|}{ M stage, n (\%) } \\
\hline M0 & $30(100)$ & $20(100)$ & 0.999 \\
\hline M1 & $0(0)$ & 0 & \\
\hline \multicolumn{4}{|l|}{ Surgical treatment, n (\%) } \\
\hline $\begin{array}{l}\text { Lobectomy or subtotal } \\
\text { thyroidectomy }\end{array}$ & $21(70)$ & $19(95)$ & 0.071 \\
\hline Total Thyroidectomy & $9(30)$ & $1(5)$ & \\
\hline Completion Thyroidectomy & $11(53)$ & $3(15)$ & 0.037 \\
\hline No completion & $10(47)$ & $16(80)$ & \\
\hline \multicolumn{4}{|l|}{ Lymph Node dissection, n (\%) } \\
\hline Yes & $3(10)$ & $1(5)$ & 0.630 \\
\hline No & $27(90)$ & $19(95)$ & \\
\hline \multicolumn{4}{|l|}{ Follow up, (years) } \\
\hline Mean \pm SD & $6 \pm 3.5$ & $2 \pm 0.2$ & $<0.0001$ \\
\hline \multicolumn{4}{|l|}{ Persistence, n (\%) } \\
\hline Complete remission & $30(100)$ & $19(95)$ & 0.837 \\
\hline Persistence of disease & 0 & $1(5)$ & \\
\hline \multicolumn{4}{|l|}{ Recurrence, n (\%) } \\
\hline Yes & $0(0)$ & $3(15)$ & 0.114 \\
\hline No & $30(100)$ & $17(85)$ & \\
\hline Thyroid bed, Bone & $0(0)$ & $1(5)$ & \\
\hline Neck LNs & $0(0)$ & $1(5)$ & \\
\hline Thyroid Remnant, Neck LNs, Lung & $0(0)$ & $1(5)$ & \\
\hline
\end{tabular}

survival rate of our patients were excellent. We registered an OS = $100 \%$ with absence of recurrence, while in the Enomoto et al. study [42] all the patients were alive (OS $=100 \%$ ) but $15 \%$ of them had 
relapse. There was a different and significant surgical approach in the two studies ( $p=0.071$ ) for TT and HT. The percentage of patients subjected to a TT, including thyroidectomy completion, was significantly greater in our cases compared to the Enomoto et al. study patients. In our series, the histological examination of the residual lobe, after thyroidectomy completion, did not reveal neoplastic spread in any of the 11 cases. Therefore, we believe that the choice of the initial surgical procedure between a radical approach and a conservative one must be tailored to each pediatric patient. A precise presurgical ultrasonography is needed to estimate dimensions, localization, multifocality, lymph nodal metastasis and extrathyroid extension. The presurgical sensibility of this evaluation method for these parameters is low while US sensibility in the evaluation of regional lymph nodes is high. These parameters are known postoperatively in the histopathological reports and they are essential for the surgeon when choosing a thyroidectomy completion after a conservative approach [55-60]. Based on our excellent results in terms of the absence of relapses (compared with the results of Enomoto) it is preferable to perform a hemithyroidectomy and then a $\mathrm{CT}$, instead of performing an immediate TT, because there is a lower frequency of complications. According to Francis GL et al. [37], conservative surgery can be indicated in patients with lesions microscopically bounded to a lobe, with dimensions $\leq 4 \mathrm{~cm}$, without evident extrathyroid extension and minimal vascular invasion ( $\leq 3$ vascular foci). In patients with wide vascular invasion (>3 vascular foci) and/or if the tumor size is $>4 \mathrm{~cm}$, especially with high postoperative Tg levels, a thyroidectomy completion is recommended. Patients with multifocal neoplasm and/or dimensions $>4 \mathrm{~cm}$ and/or lymph nodal metastasis and/or distant metastasis should be treated with TT and staged postoperatively with RAI.

\section{Conclusions}

Regardless of the surgical approach, the FTC prognosis in the children and adolescents of our study (about 90\%) by MI-FTC was excellent. Despite the limitations of our study, which are our limited series of cases and the very few cases reported in the literature, loboisthmectomy seems to represent a valid surgical approach in pediatric patients diagnosed with MI-FTC. Moreover, the conservative surgical choice has the advantage of reducing the risk of postoperative complications, which can be particularly severe in children. The follow-up of young patients diagnosed with FTC and treated with TT includes: RAI therapy, postoperative scan, neck US and thyroid serum levels monitoring. After a conservative treatment (HT), a postoperative RAI therapy is no longer requested and the follow-up includes clinical exams, an annual chest X-ray, thyroid US and specific laboratory tests every six months in the first 2 years and then annually in the following 5 years. The use of thyroid hormone (Levo-thyroxin) for the suppression of TSH secretion, owing to the high sensibility of the pediatric DTC to hormonal manipulation, represents an efficient therapeutic aid after conservative surgical treatment [6].

\section{References}

[1] Spinelli C, Bertocchini A, Antonelli A, et al. Surgical therapy of the thyroid papillary carcinoma in children: experience with 56 patients $<$ or $=16$ years old. J Pediatr Surg 2004;39(10):1500-5.

[2] Dinauer CA, Breuer C, Rivkees SA. Differentiated thyroid cancer in children: diagnosis and management. Curr Opin Oncol 2008;20:59.

[3] Hogan AR, Zhuge Y, Perez EA, et al. Pediatric thyroid carcinoma: incidence and outcomes in 1753 patients. J Surg Res 2009;156:167-72.

[4] Holmes L, Hossain J, Opara F. Pediatric thyroid carcinoma incidence and temporal trends in the USA (1973-2007): race or shifting diagnostic paradigm? ISRN Oncol 2012:1-10.

[5] Vergamini LB, Frazier AL, Abrantes FL, et al. Increase in the incidence of differentiated thyroid carcinoma in children, adolescents, and young adults: a populationbased study. J Pediatr 2014;164:1481-5.

[6] Massimino M, Podda M, Spinelli C, et al. Thyroid Cancer. In: Bleyer A, Barr R, Ries L, Whelan J, Ferrari A, editors. Cancer in adolescents and young adults. Pediatric oncology, 2nd ed.Springer International Publishing AG; 2017. p. 203-30.

[7] Davies L, Welch H. Increasing incidence of thyroid cancer in United States, 19732002. JAMA 2006;295(18):2164-7.
[8] Qaisi M, Eid I. Pediatric head and neck malignancies. Oral Maxillofac Surg Clin North Am 2016;28(1):11-9.

[9] Otto KJ, Lam JS, MacMillan C, et al. Diminishing diagnosis of follicular thyroid carcinoma. Head Neck 2010;32:1629-34.

[10] Spinelli C, Strambi S, Rossi L, et al. Surgical management of papillary thyroid carcinoma in childhood and adolescence: an Italian multicenter study on 250 patient. J Endocrinol Invest 2016;39(9):1055-9.

[11] Spinelli C, Tognetti F, Rallo L, et al. Pediatric versus adult papillary thyroid carcinoma: different diseases requiring different surgical approaches. J Head Neck Spine Surg 2017;1(1):555554.

[12] Kim J, Sun Z, Adam MA, et al. Predictors of nodal metastasis in pediatric differentiated thyroid cancer. J Pediatr Surg 2017;52(1):120-3.

[13] De Crea C, Raffaelli M, Sessa L, et al. Actual incidence and clinical behavior of follicular thyroid carcinoma: an institutional experience. Sci World J 2014;4(2014):952095.

[14] Ron E, Lubin JH, Shore RE, et al. Thyroid cancer after exposure to external radiation: a pooled analysis of seven studies. Radiat Res 1995;141:259-77.

[15] Pacini F, Vorontsova T, Demidchik EP, et al. Post-Chernobyl thyroid carcinoma in Belarus children and adolescents: comparison with naturally occurring thyroid carcinoma in Italy and France. J Clin Endocrinol Metab 1997:82:3563-9.

[16] Reiners C, Biko J, Demidchik YE, et al. Results of radioiodine treatment in children from Belarus with advanced stages of thyroid cancer after the Chernobyl accident. Chernobyl: message for the 21st century. Excerpta Medica International Congress seriesAmsterdam: Elsevier; 2002. p. 69-75.

[17] Cabanillas ME, McFadden DG, Durante C. Thyroid cancer. Lancet 2016;388(10061): 2783-95.

[18] Sklar C, Whitton J, Mertens A, et al. Abnormalities of the thyroid in survivors of Hodgkin's disease: data from the Childhood Cancer Survivor Study. J Clin Endocrinol Metab 2000;85:3227-32.

[19] Meadows AT, Friedman DL, Neglia JP, et al. Second neoplasms in survivors of childhood cancer: findings from the Childhood Cancer Survivor Study cohort. J Clin Oncol 2009;27:2356-62.

[20] Mazzaferri EL. Management of a solitary thyroid nodule. N Engl J Med 1993;328:553-9.

[21] Schneider AB, Bekerman C, Leland J, et al. Thyroid nodules in the follow-up of irradiated individuals: comparison of thyroid ultrasound with scanning and palpation. J Clin Endocrinol Metab 1997;82:4020-7.

[22] Ito M, Yamashita S, Ashizawa K, et al. Childhood thyroid diseases around Chernobyl evaluated by ultrasound examination and fine needle aspiration cytology. Thyroid 1995;5:365-8.

[23] Demidchik YE, Saenko VA, Yamashita S. Childhood thyroid cancer in Belarus, Russia, and Ukraine after Chernobyl and at present. Arq Bras Endocrinol Metabol 2007;51: 748-62.

[24] Li Volsi VA, Abrosimov AA, Bogdanova T, et al. The Chernobyl thyroid cancer experience: pathology. Clin Oncol (R Coll Radiol) 2011;23:261-7.

[25] Alzahrani AS, Murugan AK, Qasem E, et al. Single point mutations in pediatric differentiated thyroid cancer. Thyroid 2017;27(2):189-96.

[26] Nikiforov YE, Nikiforova MN. Molecular genetics and diagnosis of thyroid cancer. Nat Rev Endocrinol 2011;7:569-80.

[27] De Lellis RA. Pathology and genetics of thyroid carcinoma. J Surg Oncol 2006;94: 662-9.

[28] Smith JR, Marqusee E, Webb S, et al. Thyroid nodules and cancer in children with PTEN hamartoma tumor syndrome. J Clin Endocrinol Metab 2011;96:34-7.

[29] Ngeow J, Mester J, Rybicki LA, et al. Incidence and clinical characteristics of thyroid cancer in prospective series of individuals with Cowden and Cowden-like syndrome characterized by germline PTEN, SDH, or KLLN alterations. J Clin Endocrinol Metab 2011;96:E2063-71.

[30] Sam AH, Dhillo WS, Donaldson M, et al. Serum phosphate predicts temporary hypocalcaemia following thyroidectomy. Clin Endocrinol (Oxf) 2011:74:388-93.

[31] Liaw D, Marsh DJ, Li J, et al. Germline mutations of the PTEN gene in Cowden disease, an inherited breast and thyroid cancer syndrome. Nat Genet 1997;16:64-7.

[32] Nagy R, Ganapathi S, Comeras I, et al. Frequency of germline PTEN mutations in differentiated thyroid cancer. Thyroid 2011;21:505-10.

[33] Scholz S, Smith JR, Chaignaud B, et al. Thyroid surgery at Children's Hospital Boston: a 35-year single-institution experience. J Pediatr Surg 2011;46:437-42.

[34] De Lellis RA, Lloyd RV, Heitz PU, et al. World Health Organization classification of tumors: pathology and genetics of tumors of endocrine organs. Lyon: IARC Press; 2004; 64-6.

[35] Hedinger C, Williams ED, Sobin LH. Histological typing of thyroid tumours. International histological classification of tumors, vol. 11. Berlin, Germany: Springer-Verlag: 1988; 7-68.

[36] Hedinger C, Williams ED, Sobin LH. The WHO histological classification of thyroid tumors: a commentary on the second edition. Cancer 1989;63:908-11.

[37] Francis GL, Waguespack SG, Bauer AJ, et al. Management guidelines for children with thyroid nodules and differentiated thyroid cancer. Thyroid 2015;25(7): 716-59.

[38] Dionigi G, Kraimps JL, Schmid KW, et al. Minimally invasive follicular thyroid cancer (MI-FTC) a consensus report of the European Society of Endocrine Surgeons (ESES). Langenbecks Arch Surg 2014;399:165-84.

[39] Muratli A, Erdogan N, Sevim S, et al. Diagnostic efficacy and importance of fineneedle aspiration cytology of thyroid nodules. J Cytol 2014;31(2):73-8.

[40] Kowalski LP, Goncalves Joao, Filho J, et al. Long-term survival rates in young patients with thyroid carcinoma. Arch Otolaryngol Head Neck Surg 2003;129:746-9.

[41] Podda M, Saba A, Porru F, et al. Follicular thyroid carcinoma: differences in clinical relevance between minimally invasive and widely invasive tumors. World J Surg Oncol 2015;13:193.

[42] Enomoto K, Enomoto Y, Uchino S, et al. Follicular thyroid cancer in children and adolescents: clinicopathologic features, long-term survival, and risk factors for recurrence. Endocr J 2013;60(5):629-35. 
[43] Zou CC, Zhao ZY, Liang L. Childhood minimally invasive follicular carcinoma: clinical features and immunohistochemistry analysis. J Pediatr Child Health 2010;46: $166-70$.

[44] Kim SH, Kosnik E, Madden C, et al. Lytic skull metastasis from a follicular thyroid carcinoma in a child. Pediatr Neurosurg 1998;28:84-8.

[45] Edge SB, Byrd DR, Compton CC, et al. AJCC cancer staging manual. 7th ed. New York, NY: Springer-Verlag; 2010.

[46] Pacini F, Castagna MG, Brilli L, et al. Thyroid cancer: ESMO clinical practice guidelines for diagnosis, treatment and follow-up. Ann Oncol 2010;21(Suppl. 5):v214-9.

[47] American Thyroid Association (ATA) Guidelines Taskforce on Thyroid Nodules and Differentiated Thyroid Cancer, Cooper DS, Doherty GM, et al. Revised American Thyroid Association management guidelines for patients with thyroid nodules and differentiated thyroid cancer. Thyroid 2009;19(11):1167-214.

[48] Nixon AM, Provatopoulou X, Kalogera E, et al. Circulating thyroid cancer biomarkers: current limitations and future prospects. Clin Endocrinol (Oxf) 2017:87(2):117-26.

[49] Guilmette J, Nosé V. Hereditary and familial thyroid tumours. Histopathology 2018; 72(1):70-81.

[50] Khan NE, Bauer AJ, Schultz KAP, et al. Quantification of thyroid cancer and multinodular goiter risk in the DICER1 syndrome: a family-based cohort study. J Clin Endocrinol Metab 2017;102(5):1614-22.

[51] Bleyer WA, OLeary M, Barr R, Ries LAG (eds). Cancer epidemiology in older adolescents and young adults 15 to 29 years of age, including SEER incidence and survival, 1975-2000. National Cancer Institute (2006), Bethesda; [NIH Pub. No. 065767, also available at www.seer.cancer.gov/publications
[52] Gatta G, Capocaccia R, Stiller C, et al. The Eurocare working group childhood cancer survival trends in Europe: a EUROCARE working group study. J Clin Oncol 2005;23: 3742-51.

[53] Sugino K, Ito K, Nagahama M, et al. Prognosis and prognostic factors for distant metastases and tumor mortality in follicular thyroid carcinoma. Thyroid 2011;21:751-7.

[54] Furlan JC, Bedard YC, Rosen IB. Clinicopathologic significance of histologic vascular invasion in papillary and follicular thyroid carcinomas. J Am Coll Surg 2004;198: 341-8.

[55] Guidoccio F, Grosso M, Orsini F, et al. The Thyroid ultrasound and other imaging procedures in the pediatric age. Curr Pediatr Rev 2016;12(4):253-4.

[56] Antonelli A, Miccoli P, Fallahi P, et al. Role of neck ultrasonography in the follow-up of children operated on for thyroid papillary cancer. Thyroid 2003;13(5):479-84

[57] Massimino M, Evans DB, Podda M, et al. Thyroid cancer in adolescents and young adults. Pediatr Blood Cancer 2018. https://doi.org/10.1002/pbc.27025 [Epub ahead of print].

[58] Pyo JS, Sohn JH, Kang G. Detection of tumor multifocality is important for prediction of tumor recurrence in papillary thyroid microcarcinoma: a retrospective study and meta-analysis. J Pathol Transl Med 2016;50(4):278-86.

[59] Kim H, Kim JA, Son EJ, et al. Preoperative prediction of the extrathyroidal extension of papillary thyroid carcinoma with ultrasonography versus MRI: a retrospective cohort study. Int J Surg 2014;12(5):544-8.

[60] Spinelli C, Tognetti F, Strambi S, et al. Cervical lymph node metastases of papillary thyroid carcinoma, in the central and lateral compartments in children and adolescences: predictive factors. World J Surg 2018 [in press] https://doi.org/10.1007/ s00268-018-4487-z. 